\title{
Effect of sialylation and complexity of FSH oligosaccharides on inhibin production by granulosa cells
}

\author{
Nazareth Loreti, Verónica Ambao, Luz Andreone, Romina Trigo, Ursula Bussmann \\ and Stella Campo \\ Centro de Investigaciones Endocrinológicas (CEDIE/CONICET), Hospital General de Niños 'Ricardo Gutiérrez', \\ Gallo 1330, C1425EFD, Ciudad de Buenos Aires, Argentina and ${ }^{1}$ Instituto de Biología y Medicina Experimental \\ (IBYME/CONICET), Ciudad de Buenos Aires, Argentina
}

Correspondence should be addressed to N Loreti; Email: nloreti@cedie.org.ar

\begin{abstract}
Granulosa cell (GC) inhibin A and B production is regulated by FSH and gonadal factors. This gonadotrophin is released as a mixture of glycoforms, which induce different biological responses in vivo and in vitro. Our aim was to determine the effect of recombinant human FSH (rhFSH) glycosylation variants on inhibin A and B production by rat GCs. Preparative isoelectro focusing was used to isolate more acidic/sialylated $(\mathrm{pH}<4.00)$ and less acidic/sialylated $(\mathrm{pH}>5.00)$ rhFSH charge analogues. Concanavalin $\mathrm{A}$ was used to isolate unbound and firmly bound rhFSH glycoforms on the basis of their oligosaccharide complexity. GCs, obtained from oestrogen-primed immature rats, were cultured with either native rhFSH or its glycosylation variants. Inhibin A and B were determined using specific ELISAs. Results were expressed as mean \pm s.E.M. Under basal conditions, inhibin A was the predominant dimer produced (inhibin A: $673 \pm 55$; inhibin B: $80 \pm 4 \mathrm{pg} / \mathrm{ml}$ ). More acidic/sialylated charge analogues stimulated inhibin B production when compared to inhibin A at all doses studied; by contrast, less acidic/sialylated charge analogues stimulated inhibin A production and elicited no effect on inhibin B. Glycoforms bearing complex oligosaccharides showed a potent stimulatory effect on inhibin B when compared to inhibin A production (i.e. dose $1 \mathrm{ng} / \mathrm{ml}: 4.9 \pm 0.5$ vs $0.9 \pm 0.1$-fold stimulation, $P<0.001$ ). Glycoforms bearing hybrid-type oligosaccharides favoured inhibin A production (i.e. dose $4 \mathrm{ng} / \mathrm{ml} 2.9 \pm 0.1$ vs $1.6 \pm 0.1$-fold stimulation, $P<0.05$ ). These results show that the sialylation degree as well as the complexity of oligosaccharides present in the rhFSH molecule may be considered additional factors that differentially regulate dimeric inhibin production by rat GCs.

Reproduction (2013) 145 127-135
\end{abstract}

\section{Introduction}

Inhibin A and B are the relevant forms of circulating dimeric inhibins in human and rodents; changes in their plasma concentration during the menstrual/oestrous cycle have been described. In women, inhibin B levels are maximal in the mid-follicular phase and fall before ovulation, remaining low during the luteal phase, whereas inhibin A remains low during the early- and mid-follicular phase and predominates in the luteal phase of the menstrual cycle (Groome et al. 1994, 1996, Sehested et al. 2000). In female rats, inhibin B serum levels peak early in the oestrous cycle, whereas circulating inhibin A increases gradually until just before the primary gonadotrophin surge (Woodruff et al. 1996, Arai et al. 2002). The regulation of dimeric inhibin production is complex; FSH, growth factors and the stage of follicle development contribute to the differential regulation of inhibin $A$ and $B$. We have previously shown that rat granulosa cells (GCs) are able to secrete dimeric inhibins; this production, as well as the ratio between inhibin $A$ and $B$, is regulated by $F S H$, oestrogen and growth factors. Inhibin A seems to be more sensitive to FSH stimulation during the later stages of follicular growth, whereas inhibin B seems to reflect the action of the members of the TGF- $\beta$ superfamily in preantral follicles (Lanuza et al. 1999).

FSH is secreted in multiple glycosylation variants, which differ from each other in their sialic acid content and inner carbohydrate structure (Ulloa-Aguirre et al. 1999). Specific patterns of FSH glycoforms are associated with the degree of ovarian activity. We have previously shown that a characteristic feature of serum $\mathrm{FSH}$ in the follicular phase of young women, whose inhibin B levels are within the normal range, is the predominance of an acidic mix of FSH glycosylation variants, bearing highly branched oligosaccharides. By contrast, during the perimenopause and lactational amenorrhoea, two conditions characterized by diminished ovarian activity in the presence of normal immunoreactive FSH circulating levels, there is a 
decrease in the relative proportion of glycosylation variants bearing highly branched oligosaccharides and appear in circulation those bearing incomplete, hybrid type carbohydrate chains. These changes in the microheterogeneity of circulating FSH were associated with a significant decrease in inhibin B serum levels (Velasquez et al. 2006, Loreti et al. 2009).

In rodents, FSH sialylation varies according to the day and time of the oestrous cycle (Ulloa-Aguirre et al. 1988). Furthermore, it has been shown that the structure of oligosaccharides present in the FSH molecule induces a differential response in rat GCs in terms of oestradiol production (Ulloa-Aguirre et al. 1995). The pattern of follicular development and oocyte quality in mice are also strongly influenced by rhFSH sialylation (Nayudu et al. 2002).

It remains to be established whether the structure of the oligosaccharides present in the FSH molecule may affect other aspects of the endocrine activity in GCs. The aim of this study was to determine the effect of recombinant human $\mathrm{FSH}(\mathrm{rhFSH})$ sialylation and carbohydrate complexity on inhibin A and B GC production.

\section{Results}

The isolation of rhFSH glycosylation variants according to their sialylation degree and oligosaccharide complexity was carried out as depicted in Fig. 1.

\section{Distribution profile of rhFSH charge analogues}

The relative proportion of rhFSH charge analogues recovered in $0.29 \mathrm{pH}$ units, after preparative isoelectric focusing (IEF), is shown in Fig. 2A. The gonadotrophin was detected in 12 fractions of the gradient, within a
$\mathrm{pH}$ range of 3.20-5.90. A predominant proportion $(35.9 \pm 4.8 \%, P<0.001)$ of $\mathrm{rhFSH}$ charge analogues focused at a $4.40-4.69 \mathrm{pH}$ interval. A lower proportion of the hormone was isolated either below $\mathrm{pH} 4.10$ $(22.8 \pm 8.3 \%)$ or above $\mathrm{pH} 5.00(17.0 \pm 1.7 \%)$. In order to obtain a more acidic/sialylated charge analogues mix (rhFSH-AC), fractions from $\mathrm{pH} 2.56$ to 4.00 were combined and concentrated; fractions at $\mathrm{pH}>5.00$ were combined to obtain a less acidic/sialylated preparation (rhFSH-BA). These two rhFSH preparations were selected to explore the effect of their sialylation degree on inhibin production, based on the previously observed variations in the relative proportion of circulating gonadotrophin isolated at these two $\mathrm{pH}$ intervals that were associated with changes in ovarian activity in normal women (Velasquez et al. 2006, Loreti et al. 2009).

\section{Distribution profile of native rhFSH glycoforms after concanavalin A chromatography}

In order to isolate rhFSH glycosylation variants on the basis of its carbohydrate complexity, concanavalin A (ConA) chromatography was used. The three groups of glycoforms disclosed by lectin were detected in native rhFSH: unbound glycoforms bearing complex, triantennary and bisecting oligosaccharides ( $\mathrm{rhFSH}-\mathrm{UB}$ ); weakly bound glycoforms bearing biantennary and truncated oligosaccharides (rhFSH-WB), and firmly bound glycoforms bearing high mannose and hybridtype oligosaccharides (rhFSH-FB). A clear predominance of glycoforms bearing high mannose and hybrid-type oligosaccharides was observed $(70.7 \pm 4.9 \%$ vs 18.3 $\pm 4.7 \%$ and $12.3 \pm 3.5 \%$, rhFSH-FB vs rhFSH-WB and rhFSH-UB respectively, $P<0.001$ ) (Fig. 2B). To confirm this finding, rhFSH-FB glycoforms were re-analysed in a

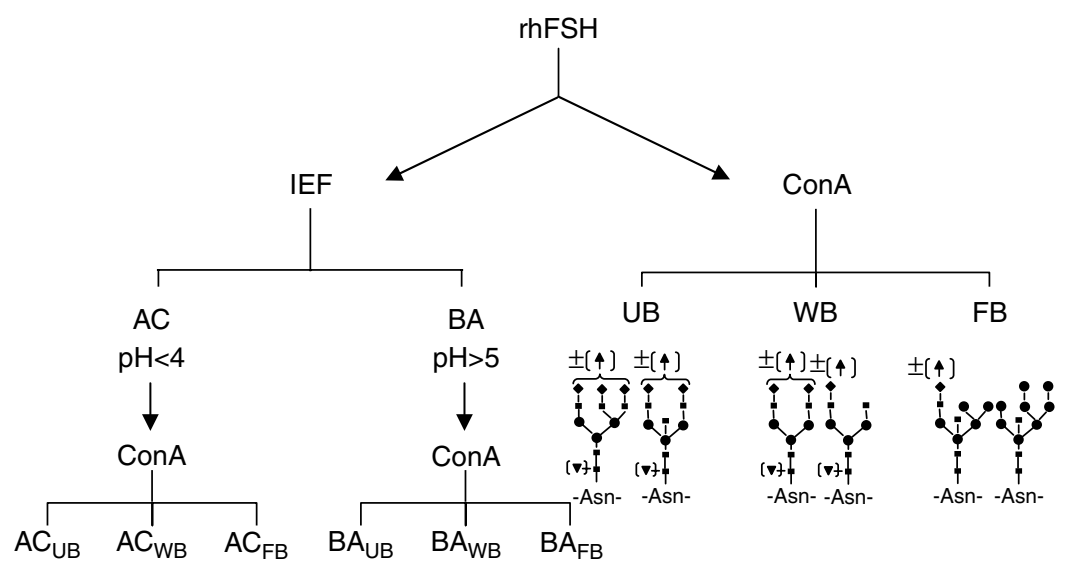

Figure 1 General outline of the analytical procedure followed to isolate and characterize rhFSH glycosylation variants according to their charge (IEF, preparative isoelectric focusing) and oligosaccharide complexity (ConA, concanaval in A chromatography). AC: more acidic charge analogues isolated at $\mathrm{pH}<4$; BA: less sialylated charge analogues isolated at $\mathrm{pH}>5$. Oligosaccharide structures of rhFSH glycoforms isolated after ConA chromatography are shown: UB, unbound, triantennary and bisecting oligosaccharides; WB, weakly bound, biantennary and truncated oligosaccharides; and FB, firmly bound, high mannose and hybrid-type oligosaccharides. $\mathrm{AC} \mathrm{CB}_{\mathrm{B}, \mathrm{WB}, \mathrm{FB}}$, unbound, weakly and firmly bound more acidic charge analogues; $\mathrm{B} \mathrm{A}_{\cup \mathrm{B}, \mathrm{WB}, \mathrm{FB}}$ unbound, weakly and firmly bound less sialylated charge analogues. Asn, asparagine; closed square, $\mathrm{N}$-acetylglucosamine; closed circle, mannose; closed diamond, galactose; closed down triangle, fucose; uparrow, sialic acid; \pm with or without sialic acid. 

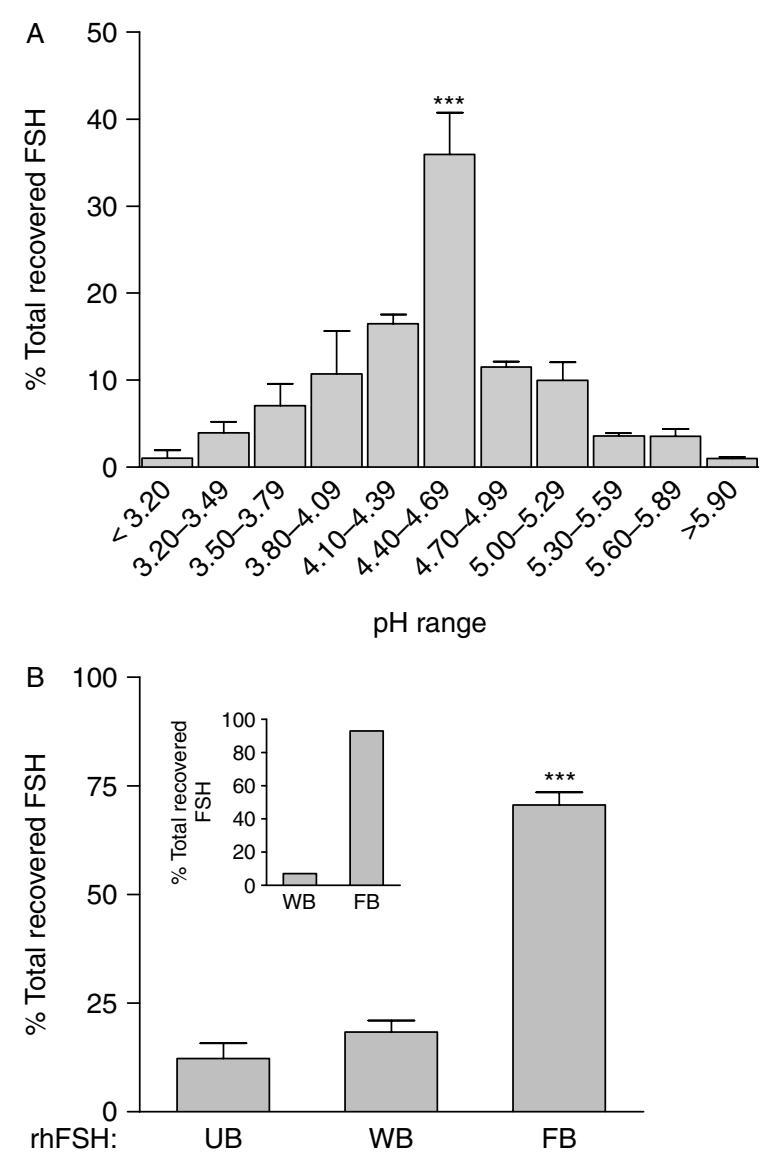

Figure 2 Distribution profile of rhFSH charge analogues after IEF, isolated within $\mathrm{pH}$ intervals of 0.29 units in a $\mathrm{pH} 3-10$ gradient (A). Distribution profile of rhFSH glycosylation variants isolated by concanavalin A chromatography (B): unbound (rhFSH-UB: triantennary and bisecting oligosaccharides); weakly bound (rhFSH-WB: biantennary and truncated oligosaccharides) and firmly bound (rhFSH-FB: high mannose and hybrid-type oligosaccharides). Inset: Re-chromatography of rhFSH-FB fraction. Results are expressed as mean \pm s.E.M. percentage of total recovered rhFSH of triplicate incubations of three independent experiments. ${ }^{* * *} P<0.001$, proportion of $\mathrm{rhFSH}$ isolated at a $\mathrm{pH}$ interval of 4.40-4.69 vs those isolated at $\mathrm{pH}$ intervals above and below these values $(\mathrm{A}) .{ }^{* * *} \mathrm{P}<0.001, \mathrm{rhFSH}-\mathrm{FB}$ proportion vs rhFSH-UB and rhFSH-WB proportions (B).

new ConA column; $90 \%$ of the hormone was again firmly bound to the lectin.

To explore the effect of rhFSH carbohydrate complexity on inhibin production by GCs, glycoforms bearing complex oligosaccharides and those bearing high mannose and hybrid-type oligosaccharides, with marked differences in the complexity of their oligosaccharides, were selected. In previous studies, we found that it was the relative proportion of these two types of glycosylation variants that were more affected by changes in ovarian cyclicity and ageing in normal women. FSH glycoforms, bearing triantennary and bisecting oligosaccharides, circulate in the follicular phase of the normal menstrual cycle, when a fully functional gonad is present; however, they are absent in postmenopausal women (Creus et al. 1996, Velasquez et al. 2006). During the perimenopause, there is a relative decrease in circulating FSH glycoforms bearing triantennary and bisecting oligosaccharides, concomitantly with the appearance of a small proportion of glycosylation variants bearing high mannose and hybrid-type oligosaccharides (Loreti et al. 2009).

\section{Distribution profile of more and less sialylated rhFSH after ConA chromatography}

The more acidic/sialylated and the less sialylated rhFSH charge analogues (rhFSH-AC and rhFSH-BA) were concentrated and individually applied to ConA columns in order to characterize the glycosylation variants on the basis of their oligosaccharide complexity (Fig. 3A and $\mathrm{B})$. A clear predominance of rhFSH glycoforms bearing complex oligosaccharides was observed when the more acidic/sialylated rhFSH charge analogue preparation was analysed ( $\mathrm{rhFSH}-\mathrm{AC}_{\mathrm{UB}}$ : $39.5 \pm 5.5 \%$ and $\mathrm{rhFSH}-\mathrm{AC}_{\mathrm{WB}}: 45.5 \pm 7.5 \%$ of total recovered $\mathrm{rhFSH})$; a lower proportion of glycoforms bearing high mannose and hybrid-type oligosaccharides was found (rhFSH-AC $\mathrm{FB} 15.0 \pm 2.0, P<0.01$ ).

rhFSH glycoforms bearing high mannose and

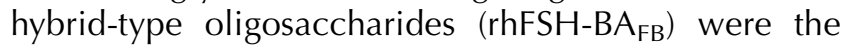
more abundant glycosylation variants found in the less acidic preparation $(83.8 \pm 7.7 \%$ vs $13.0 \pm 6.1 \%$ and $3.3 \pm 1.8 \%$, rhFSH-BA $F B$ vs rhFSH-BA ${ }_{W B}$ and rhFSH-BA ${ }_{\cup B}$ respectively, $\left.P<0.001\right)$.

\section{Effect of native rhFSH on inhibin $A$ and $B$ production}

Rat GCs, cultured under basal conditions, predominantly produced inhibin $A$ (inhibin $A, 673 \pm 55$; inhibin B, $80 \pm 4 \mathrm{pg} / \mathrm{ml}$ ); the INHA/INHB ratio was $8.4 \pm 0.3$. To assess the effect of rhFSH on the production of both inhibins, GCs were cultured with increasing doses of gonadotrophin $(0.5-16 \mathrm{ng} / \mathrm{ml})$. As shown in Table 1, rhFSH favoured inhibin A production; the lowest dose used $(0.5 \mathrm{ng} / \mathrm{ml})$ was able to significantly stimulate the production of this dimer $(P<0.01$ when compared to basal). The lowest dose of rhFSH that was effective to induce an increase in inhibin $B$ secretion was $4 \mathrm{ng} / \mathrm{ml}$ $(P<0.05$ when compared to basal).

\section{Effect of rhFSH sialylation on inhibin $A$ and $B$ production}

When rat GCs were stimulated with more and less acidic/sialylated rhFSH charge analogues, there was a differential effect on inhibin production depending on the charge analogues mix to which the cells were exposed (Fig. 4). More acidic/sialylated charge analogues isolated at $\mathrm{pH}$ below 4 (rhFSH-AC) stimulated inhibin B production (3.6- to 13.7-fold over basal, 

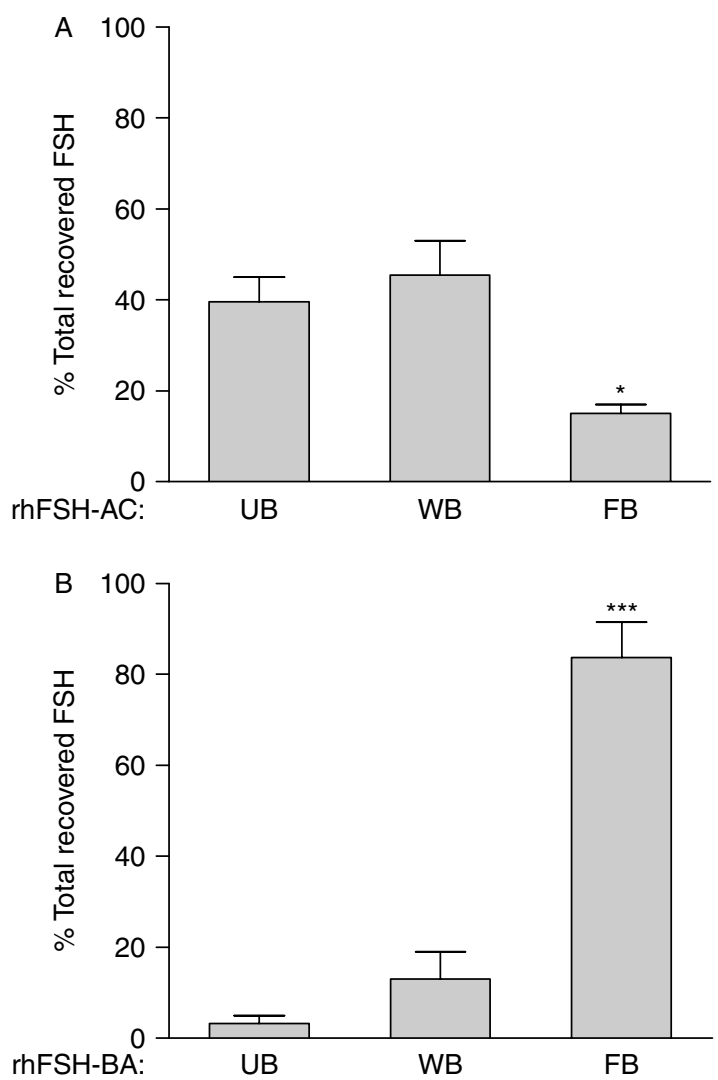

Figure 3 Distribution profile of rhFSH charge analogues after concanavalin A chromatography. rhFSH-AC: more acidic charge analogues isolated at $\mathrm{pH}<4(\mathrm{~A})$; rhFSH-BA: less sialylated charge analogues isolated at $\mathrm{pH}>5(\mathrm{~B})$. rhFSH- $\mathrm{AC}_{\mathrm{UB}}$, unbound, triantennary and bisecting oligosaccharides; rhFSH-AC $\mathrm{WB}_{\mathrm{B}}$, weakly bound, biantennary and truncated oligosaccharides and $\mathrm{rhFSH}-\mathrm{AC}_{\mathrm{FB}}$, firmly bound, high mannose and hybrid-type oligosaccharides. Results are expressed as mean \pm S.E.M. percentage of total recovered $\mathrm{rhFSH}$ of triplicate incubations of three independent experiments. ${ }^{*} P<0.05 ;{ }^{* * *} P<0.001$, FB proportion vs UB and WB proportions.

$P<0.01$ ) over a dose range of $1-16 \mathrm{ng} / \mathrm{ml}$. Only minor changes were observed in inhibin A production, even at the highest doses $(8$ and $16 \mathrm{ng} / \mathrm{ml}$ ) used in the culture: 1.3- and 2.9-fold stimulation over basal respectively. By contrast, the cells exposed at the less acidic/sialylated counterparts isolated at $\mathrm{pH}$ above 5 (rhFSH-BA) responded with a marked increment of inhibin $A$ secretion (from 4.9- to 7.6-fold stimulation over basal) at a dose range of $2-16 \mathrm{ng} / \mathrm{ml}$; no effect was observed on inhibin B production at any of the doses studied.

\section{Effect of rhFSH glycan branching}

The complexity of rhFSH oligosaccharides also affected dimeric inhibin production (Fig. 5). Both rhFSH glycosylation variants, rhFSH-UB and rhFSH-FB, stimulated the production of inhibin $\mathrm{A}$ and $\mathrm{B}$; however, those bearing triantennary and bisecting oligosaccharides (rhFSH-UB) clearly favoured inhibin B production. A significant increment was observed at a low dose, $1 \mathrm{ng} / \mathrm{ml}: 4.9 \pm$ 0.5 -fold stimulation over basal $(P<0.05)$; maximal stimulation was reached at the dose of $2 \mathrm{ng} / \mathrm{ml}(6.9 \pm$ 0.4 -fold stimulation over basal). Under these experimental conditions, inhibin A was not affected. Higher doses of rhFSH-UB glycoforms were needed to significantly increase inhibin A production: $4-16 \mathrm{ng} / \mathrm{ml}$ (1.9to 7.5 -fold stimulation over basal, $P<0.01$ ) (Fig. 5A).

rhFSH glycoforms bearing high mannose and hybridtype oligosaccharides (rhFSH-FB fraction) stimulated inhibin A production over a range of doses between 4 and $16 \mathrm{ng} / \mathrm{ml}$ (2.9- to 9.0-fold stimulation over basal, $P<0.001)$. Minor changes were observed in inhibin $B$ production at the highest doses used in the culture (Fig. 5B).

\section{Discussion}

The differential actions of $\mathrm{FSH}$ glycosylation variants on GC function and follicular development have been previously reported (Ulloa-Aguirre et al. 1995, Vitt et al. 1998). The results obtained in this study show, for the first time, that this differential action of FSH glycosylation on GCs also affects inhibin production.

rhFSH was used to isolate glycosylation variants, based on their carbohydrate sialylation and complexity, considering that this preparation is extremely pure and has no LH contamination (Loumaye et al. 1995). The results obtained herein confirmed previous reports describing the isolation of rhFSH charge analogues within a $\mathrm{pH}$ range similar to that found in this study; the predominant proportion of the gonadotrophin was also isolated at a similar $\mathrm{pH}$ interval (Horsman et al. 2000). Nevertheless, the proportion of more acidic/ sialylated charge analogues (isolated below $\mathrm{pH}$ 4.4) was clearly lower in the rhFSH preparation when compared with that physiologically secreted during the follicular phase of the normal menstrual cycle (Zambrano et al. 1995, Velasquez et al. 2006, Loreti et al. 2009). When the carbohydrate complexity of glycosylation variants was analysed, a clear predominance of glycoforms bearing incomplete carbohydrates was found in

Table 1 Effect of native rhFSH on inhibin A and B production by rat granulosa cells.

\begin{tabular}{lccccccc}
\hline rhFSH $(\mathrm{ng} / \mathrm{ml})$ & $\mathbf{0}$ & $\mathbf{0 . 5}$ & $\mathbf{1}$ & $\mathbf{2}$ & $\mathbf{4}$ & $\mathbf{8}$ & $\mathbf{1 6}$ \\
\hline INHA $(\mathrm{pg} / \mathrm{ml})$ & $673 \pm 55$ & $1117 \pm 86^{+}$ & $1142 \pm 54^{+}$ & $1397 \pm 151^{\ddagger}$ & $1854 \pm 185^{\ddagger}$ & $2368 \pm 200^{\ddagger}$ & $4159 \pm 69^{\ddagger}$ \\
INHB (pg/ml) & $80 \pm 4$ & $82 \pm 7$ & $100 \pm 13$ & $123 \pm 15$ & $129 \pm 5^{*}$ & $174 \pm 17^{\ddagger}$ & $338 \pm 27^{\ddagger}$ \\
\hline
\end{tabular}

Rat granulosa cells were cultured for $72 \mathrm{~h}$ with or without increasing concentrations of native recombinant human FSH (rhFSH; expressed in terms of hFSH-2 standard, NIDDKNHPP). Inhibins A (INHA) and B (INHB) were determined in the conditioned media. Results are expressed as mean \pm s.E.M. of triplicate incubations of three independent experiments. ${ }^{*} P<0.05 ;{ }^{+} P<0.01 ;{ }^{\ddagger} P<0.001$ compared with respective control. 

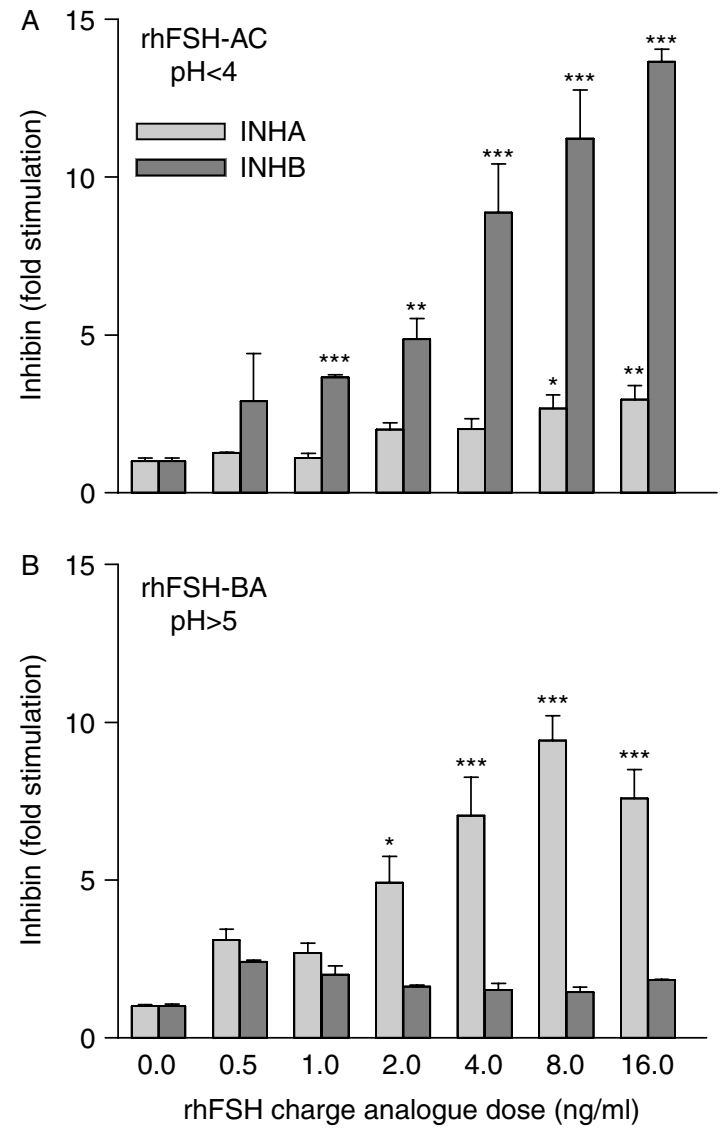

Figure 4 Effect of sialylation degree of rhFSH on inhibin A (INHA) and inhibin B (INHB) production by rat granulosa cells (GCs). GCs were cultured with or without increasing concentrations of more acidic charge analogues isolated at $\mathrm{pH}<4, \mathrm{rhFSH}-\mathrm{AC}(\mathrm{A})$, and less acidic charge analogues isolated at $\mathrm{pH}>5$, rhFSH-BA (B). The rhFSH dose is expressed in terms of $\mathrm{hFSH}-2$ standard (NIDDKNHPP). Inhibin $\mathrm{A}$ and $\mathrm{B}$ were determined in the conditioned media after $72 \mathrm{~h}$ of culture. Results are presented as fold stimulation over respective basal production. Values are mean \pm S.E.M. of triplicate incubations of three independent experiments. ${ }^{*} P<0.05 ;{ }^{* *} P<0.01 ;{ }^{* * *} P<0.001$ compared with respective control.

this preparation. These results were not unexpected considering the source of production of this hormone, the $\mathrm{CHO}$ cells. This non-human cell line does not express $\beta$-galactoside $\alpha 2,6$-sialyltransferase and $\mathrm{N}$-acetylglucosaminyltransferase III. Therefore, only a2,3-linked sialic acid residues are added to rhFSH carbohydrate chains and there is no possibility to add bisecting GlcNAc residues to generate oligosaccharide complex structures (Hård et al. 1990, Xu et al. 2011). Interestingly, the physiologically produced $\mathrm{FSH}$ in the human pituitary contains not only $\alpha 2,3$-linked but also a2,6-linked sialic acid residues (Green \& Baenziger 1988), and glycoforms bearing complex oligosaccharides are predominant in human pituitary extracts (Creus et al. 2001). It is worth noting that the differences in the characteristic of the carbohydrates present in the FSH molecule, currently used to stimulate follicular development and ovulation, may have a relevant impact on GC endocrine function.

It has been demonstrated that differences in FSH sialylation affect GC as well as follicular functions. In particular, a differential regulation induced by pituitary FSH charge analogues on inhibin $\alpha$-subunit expression has been reported using a similar experimental model (Timossi et al. 2000). Our results showed that the sialylation degree of rhFSH is involved in the differential secretion of a specific inhibin dimer. It was clear that more sialylated rhFSH favoured inhibin B production; the less sialylated counterparts were not able to stimulate inhibin B but exerted a marked stimulatory effect on inhibin A. This particular effect exerted by the rhFSH degree of sialylation on the GC may contribute to the characteristic pattern of dimeric inhibin secretion profile
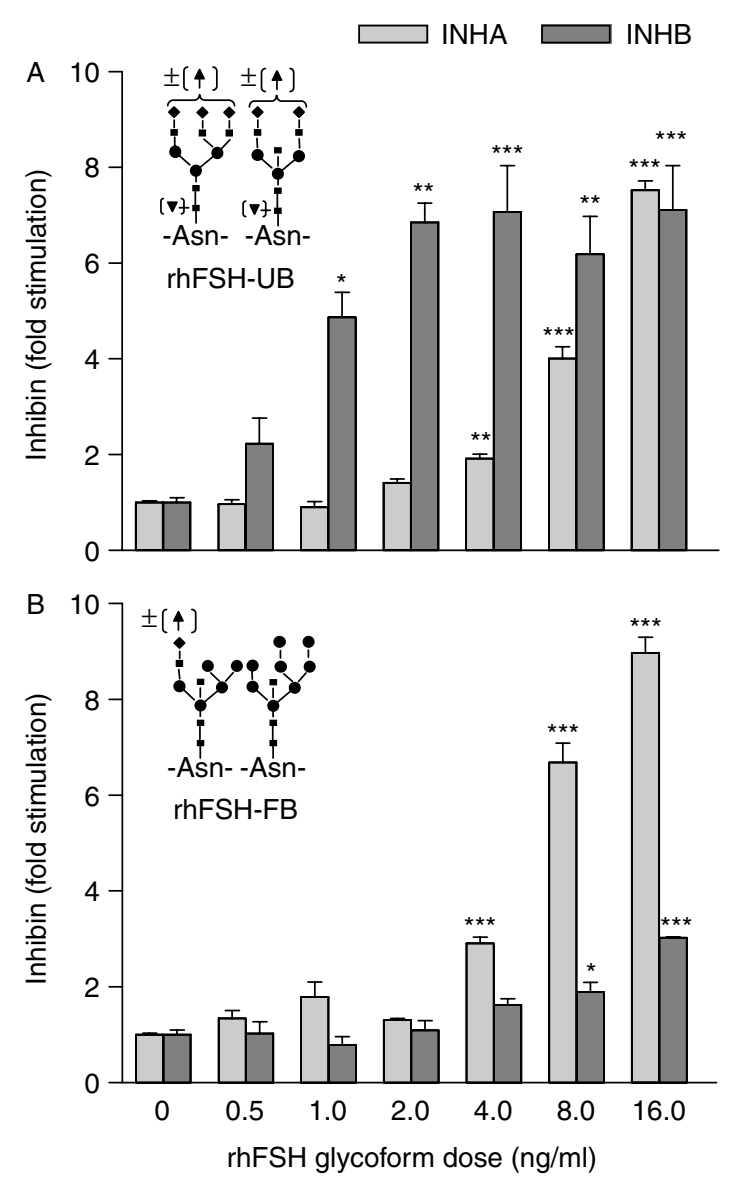

Figure 5 Effect of rhFSH glycan branching on inhibin $\mathrm{A}$ (INHA) and inhibin B (INHB) production by rat granulosa cells (GCs). GCs were cultured with or without increasing concentrations of rhFSH glycoforms bearing triantennary and bisecting oligosaccharides (rhFSH-UB; A) and glycoforms bearing high mannose and hybrid-type oligosaccharides (rhFSH-FB; B). The rhFSH dose is expressed in terms of $\mathrm{hFSH}-2$ standard (NIDDKNHPP). Inhibin A and B were determined in the conditioned media after $72 \mathrm{~h}$ of culture. Results are presented as fold stimulation over respective basal production. Values are mean \pm S.E.M. of triplicate incubations of three independent experiments. ${ }^{*} P<0.05 ;{ }^{* *} P<0.01$; ${ }^{* * *} P<0.001$ compared with respective control. 
observed across the menstrual cycle. FSH sialic acid content varies across the menstrual cycle (Padmanabhan et al. 1988, Zambrano et al. 1995); concomitantly with the presence of more acidic FSH, raising serum inhibin B concentrations are observed in the early follicular phase of the menstrual cycle, whereas the less acidic counterparts found in the late follicular phase are associated with the appearance of inhibin A in circulation.

In a previous study, we showed that not only the degree of sialylation but also the complexity of the FSH carbohydrate influences the biological response in the Sertoli cell in terms of oestradiol production (Creus et al. 2001). Dimeric production in GCs was also affected by the oligosaccharide structure of rhFSH; however, it is worth noting that the differential effect induced by oligosaccharide complexity was not identical to that exerted by the degree of hormone sialylation. rhFSH glycosylation variants bearing complex oligosaccharides (rhFSH-UB) were able to stimulate inhibin A and B. Nevertheless, GCs showed a high sensitivity to respond to these glycosylation variants producing, predominantly, inhibin B. The differential effect of oligosaccharide complexity on inhibin production disappeared when cells were exposed to high doses of the hormone.

The analysis of the oligosaccharide complexity in the more and less sialylated rhFSH charge analogues revealed the predominance of oligosaccharides that have completed the addition of all sugar residues in the rhFSH-AC preparation and the presence of a very high proportion of incomplete, high mannose/ hybrid-type oligosaccharides in the rhFSH-BA preparation.

Recent studies have shown that pituitary hFSH consists of two classes of molecules: those that possess a non-glycosylated $\beta$-subunit and those that possess di-glycosylated $\beta$-subunits (Walton et al. 2001, Bousfield et al. 2007). These differences impact on the $\beta$-subunit and FSH molecular weight. It cannot be ruled out that in our preparations, particularly in rhFSH-BA and rhFSH-FB, non-glycosylated $\beta$-subunits may be present. However, the differential effects exerted by rhFSH glycosylation variants on inhibin production by GCs cannot account for variations in the gonadotrophin mass added to the cultures. The amount of native rhFSH as well as its glycosylation variants was evaluated by RIA using a polyclonal antibody that is unable to differentiate the rhFSH glycosylation variants according to their molecular weight. All the glycosylation variants isolated from rhFSH showed the same affinity for the antibody when referred to an identical standard: LER 907. This standard was previously used to evaluate immunological FSH activity when the in vitro biopotency of different hFSH preparations was assessed (Zambrano et al. 1996, Yding Andersen et al. 1999).

Based on all these findings, it can be concluded that GCs need the stimulus of an FSH molecule bearing two concomitant characteristics: a heavily sialylated carbohydrate chain and a complex carbohydrate chain in order to produce inhibin B. On the other hand, inhibin A production may not require such a strict molecular feature; it may be stimulated by an $\mathrm{FSH}$ molecule bearing different degrees of oligosaccharide complexity, but the presence of an abundant sialic acid content in the oligosaccharide moiety of the gonadotrophin might hinder the production of this dimer.

Further studies will be needed to elucidate the molecular mechanism induced by FSH glycosylation variants to exert this differential regulation on GC inhibin production. Unlike the $\alpha$ - and $\beta A$ subunits, transcription of the $\beta B$-subunit is not regulated by cAMP-responsive elements (Dykema \& Mayo 1994) and the canonical Gs/cAMP/PKA pathway is not the unique mechanism leading to FSH biological actions (Gloaguen et al. 2011). Therefore, it can be speculated that specific signal transduction pathways could be activated by FSH glycoforms in order to induce not only the expression of inhibin/activin subunits but also other genes involved in the regulation of important regulatory mechanisms of GC function.

\section{Materials and Methods}

\section{Reagents}

rhFSH was purchased from the National Hormone and Peptide Program of the National Institute of Diabetes, Digestive and Kidney Diseases (NIDDK)-NIH (Torrance, CA, USA). Diethylstilbestrol (DES) was purchased from Sigma-Aldrich, Inc. DMEM, nutrient Mixture F-12 (Ham), fungizone $(250 \mu \mathrm{g} / \mathrm{ml})$ and gentamicina $(10 \mathrm{mg} / \mathrm{ml})$, was obtained from Invitrogen. All other chemicals were of reagent grade from standard commercial sources.

\section{Rat GC isolation and culture}

Ovaries were obtained from 21- to 23-day-old immature female Sprague-Dawley rats, injected s.c. with $1 \mathrm{mg}$ DES daily for 3 days. Animals were killed by cervical dislocation, and all experimental procedures were performed in compliance with the National Institutes of Health Guide for the Care and Use of Laboratory Animals and approved by the local Institutional Ethic Committee (IBYME-CONICET). GCs were isolated by follicular puncture, as described previously (Bley et al. 1992). Cells were seeded onto plastic 96-well plates (Nunc, Roskilde, Denmark). Initial plating density was $2 \times 10^{5}$ viable cells $/ \mathrm{cm}^{2}$ and cells were maintained at $37^{\circ} \mathrm{C}$ with $5 \% \mathrm{CO}_{2}$. After $2 \mathrm{~h}$, medium was changed to remove non-attached cells and replaced with fresh DMEM:F12 (1:1, vol/vol)-bicarbonate $(2.2 \mathrm{~g} / \mathrm{l})$ supplemented with fungizone, gentamicin, in the absence or presence of native rhFSH and its glycosylation variants $(0.5-16 \mathrm{ng} / \mathrm{ml})$ for $72 \mathrm{~h}$.

\section{Isolation of rhFSH glycosylation variants}

Glycosylation variants were isolated according to either their charge or their oligosaccharide complexity. Two native rhFSH 
ampoules (40 mg LER-907) were applied for each procedure; three independent and consecutive analyses were carried out. The content of each ampoule was dissolved in double-distilled and deionized water (Barnstead NANOPure II, Thermo Scientific, Baltimore, MD, USA) and applied into a preparative IEF cell or into a ConA column.

\section{Preparative IEF}

Preparative IEF was used to isolate rhFSH charge analogues according to their sialylation degree using a Rotofor system (Rotofor Preparative Cell, Bio-Rad Laboratories, Inc.) as described previously (Bedecarrás et al. 1998, Loreti et al. 2009). Focusing was carried out at $12 \mathrm{~W}$ constant power (Power Pac 3000 Bio-Rad Laboratories, Inc.) for 4 h, maintaining the chamber refrigerated (Refrigerated Circulator, Forma Scientific, Inc., Marietta, OH, USA). Twenty fractions $(2.5 \mathrm{ml}$ each) were harvested and their $\mathrm{pH}$ was determined. Each individual fraction was exhaustively dialysed against $1 \mathrm{~mol} / \mathrm{l}$ $\mathrm{NaCl}$ to completely eliminate ampholytes and detergent and I-FSH content was determined by double-antibody RIA. The range of recovered $\mathrm{FSH}$ was $70-85 \%$. Fractions from $\mathrm{pH} 2.56$ to 4.00 (rhFSH-AC) and at $\mathrm{pH}>5.00$ (rhFSH-BA) were combined and concentrated using Centriprep-10 membrane (cut-off 10 000; Amicon, Beverly, MA, USA) and stored at $-20{ }^{\circ} \mathrm{C}$.

\section{ConA chromatography}

ConA chromatography was used to isolate three groups of rhFSH glycosylation variants according to the complexity of their oligosaccharides. The isolation of these three groups of glycoforms was based on the different affinities that the carbohydrate structures have for this particular lectin. Galactosyl residues present in glycoproteins bearing complex type or highly branched oligosaccharides do not interact with the lectin, unbound fraction: UB (Goldstein et al. 1965). On the contrary, carbohydrate chains containing two interacting $\alpha$-mannopyranosyl residue, frequently present in high mannose and hybrid-type oligosaccharides, are strongly retained in the column, firmly bound fraction: FB (Ogata et al. 1975). The presence of $\mathrm{N}$-acetylglucosamine residues, frequently present in glycoproteins bearing biantennary and truncated carbohydrate chains, considerably weakens binding to the lectin, weakly bound fraction: WB (Goldstein et al. 1965). The technique described by Narasimhan et al. (1979), modified by Cheng et al. (1984) and Creus et al. (1996), was employed. Briefly, equilibrium buffer $(50 \mathrm{~mm}$ Tris- $\mathrm{HCl}$; $\mathrm{pH} 7.4,0.5 \mathrm{M}$ $\mathrm{NaCl}, 1 \mathrm{mM} \mathrm{MgCl} 2,1 \mathrm{mM} \mathrm{CaCl}_{2}$, and $1 \mathrm{mM} \mathrm{MnCl}_{2}$ ) was used to elute unbound rhFSH glycoforms (rhFSH-UB); equilibrium buffer containing $10 \mathrm{mM}$ methyl- $\alpha$-D-glucopyranoside (glucoside) was used to elute the weakly bound rhFSH glycoforms (rhFSH-WB) and equilibrium buffer containing 0.1 M methyl- $\alpha$ D-mannopyranoside (mannoside) was used to elute the firmly bound rhFSH glycoforms (rhFSH-FB).

Eluates containing rhFSH-UB, -WB and -FB glycoforms were dialysed against $0.01 \mathrm{~mol} / \mathrm{l} \mathrm{NaCl}$ and concentrated (Centriprep membranes, Amicon). The procedure was carried out at $4{ }^{\circ} \mathrm{C}$. The range of recovered rhFSH was $75-90 \%$. The distribution profile of rhFSH glycoforms was obtained by considering each fraction as a proportion of the total rhFSH recovered after ConA chromatography.

\section{Distribution profile of rhFSH charge analogues after ConA chromatography}

More acidic/sialylated rhFSH (6.8 mg LER-907) and less sialylated $\mathrm{rhFSH}$ (5.4 mg LER-907) charge analogues were individually applied to ConA columns. Figure 1 shows the general outline of the analytical procedure. The elution protocol was identical to the one described in the previous paragraph.

\section{Hormone measurements}

The rhFSH content of samples was measured using an in-house double-antibody RIA with reagents provided by NIDDK (Bethesda, MD, USA). The RP LER-907 (1 mg LER-907= 53 IU Second International Reference Preparation, hMG) was used to construct the standard curve. The polyclonal antibody, anti-hFSH-6, was used as antiserum. Purified hFSH (hFSH-ISIAFP-1) was iodinated using the chloramine-T method (Greenwood et al. 1963). To minimize the effects of interassay variations, as well as to determine the degree of parallelism between the unknown samples and the FSH standards, all glycoform preparations were analysed at multiple dose levels in the same assay run. The intra- and interassay coefficients of variation were $<9$ and $12 \%$ respectively. Simultaneous curve fitting of the dose-response curves obtained in the RIA of the glycoforms revealed no significant differences among the slopes generated by the standard LER-907 and the different rhFSH glycosylation variants, suggesting that the glycoforms were equally recognized by the antibody. rhFSH is expressed in terms of hFSH-2 standard (NIDDKNHPP).

Inhibin A and B levels in the culture media were measured using specific two-site ELISAs (Oxford Bio-Innovation Ltd., Oxon, UK) as described previously (Groome et al. 1994, 1996). Recombinant human inhibin A and B (Genentech, San Francisco, CA, USA) were used as standards. The assay sensitivity was $7 \mathrm{pg} / \mathrm{ml}$ for inhibin A and $15 \mathrm{pg} / \mathrm{ml}$ for inhibin B. Inhibin A had $<0.5 \%$ cross-reaction in the inhibin B assay whereas inhibin $B$ had $<0.1 \%$ cross-reaction in the inhibin $A$ assay. The human inhibin A and B assays had been validated and successfully used in the rat (Lanuza et al. 1999, Arai et al. 2002).

\section{Statistical analysis}

Results are expressed as mean \pm s.E.M. Data were log transformed before statistical analysis when appropriate; percentage of FSH glycosylation variants was transformed to arcsine $(p)^{1 / 2}$, where $0<P<1$. Statistical analysis was performed using oneway ANOVA followed by the Tukey-Kramer test for multiple comparisons. The significance was established when the twotailed $P$ value was $<0.05$. All statistical analyses were performed using GraphPad Prism version 5.00 for Windows (GraphPad Software, San Diego, CA, USA). 


\section{Declaration of interest}

The authors declare that there is no conflict of interest that could prejudice the impartiality of the present research reported.

\section{Funding}

This work was supported by the Consejo Nacional de Investigaciones Científicas y Técnicas (CONICET, PIP 5479 to S Campo) and Agencia Nacional de Promoción Científica y Tecnológica (ANPCyT, PICT 25365 to S Campo).

\section{Acknowledgements}

The authors are very grateful to NIDDK-NIH's National Hormone \& Peptide Program for supplying rhFSH. S Campo is an established member of CONICET.

\section{References}

Arai KY, Ohshima K, Watanabe G, Arai K, Uehara K \& Taya K 2002 Dynamics of messenger RNAs encoding inhibin/activin subunits and follistatin in the ovary during the rat estrous cycle. Biology of Reproduction 66 1119-1126. (doi:10.1095/biolreprod66.4.1119)

Bedecarrás P, Gryngarten M, Ayuso S, Escobar ME, Bergadá C \& Campo S 1998 Characterization of serum SHBG isoforms in prepubertal and pubertal girls. Clinical Endocrinology 49 603-608. (doi:10.1046/j.13652265.1998.00574.x)

Bley MA, Simón JC, Estévez AG, de Asúa LJ \& Barañao JL 1992 Effect of follicle stimulating hormone on insulin-like growth factor-l-stimulated rat granulosa cell deoxyribonucleic acid synthesis. Endocrinology 131 1223-1229. (doi:10.1210/en.131.3.1223)

Bousfield GR, Butnev VY, Walton WJ, Nguyen VT, Huneidi J, Singh V, Kolli VS, Harvey DJ \& Rance NE 2007 All-or-none N-glycosylation in primate follicle-stimulating hormone $\beta$-subunits. Molecular and Cellular Endocrinology 260-262 40-48. (doi:10.1016/j.mce.2006.02.017)

Cheng CY, Frick J, Gunsalus GL, Musto NA \& Bardin CW 1984 Human testicular androgen-binding protein shares immunodeterminants with serum testosterone-estradiol-binding globulin. Endocrinology $\mathbf{1 1 4}$ 1395-1401. (doi:10.1210/endo-114-4-1395)

Creus S, Pellizzari E, Cigorraga S \& Campo S 1996 Human FSH isoforms: bio and immunoactivity in post-menopausal and normal menstruating women. Clinical Endocrinology 44 181-189. (doi:10.1046/j.1365-2265. 1996.646467.x)

Creus S, Chaia Z, Pellizzari EH, Cigorraga SB, Ulloa-Aguirre A \& Campo S 2001 Human FSH isoforms: carbohydrate complexity as determinant of in-vitro bioactivity. Molecular and Cellular Endocrinology 174 41-49. (doi:10.1016/S0303-7207(00)00453-6)

Dykema JC \& Mayo KE 1994 Two messenger ribonucleic acids encoding the common $\beta$ B-chain of inhibin and activin have distinct $5^{\prime}$-initiation sites and are differentially regulated in rat granulosa cells. Endocrinology 135 702-711. (doi:10.1210/en.135.2.702)

Gloaguen P, Crépieux P, Heitzler D, Poupon A \& Reiter E 2011 Mapping the follicle-stimulating hormone-induced signaling networks. Frontiers in Endocrinology 2 1-13. (doi:10.3389/fendo.2011.00045)

Goldstein IJ, Hollerman CE \& Smith EE 1965 Protein-carbohydrate interaction. II. Inhibition studies on the interaction of concanavalin A with polysaccharides. Biochemistry 4 876-883. (doi:10.1021) bi00881a013)

Green ED \& Baenziger JU 1988 Asparagine-linked oligosaccharides on lutropin, follitropin, and thyrotropin. II. Distributions of sulfated and sialylated oligosaccharides on bovine, ovine, and human pituitary glycoprotein hormones. Journal of Biological Chemistry 263 36-44.

Greenwood FC, Hunter WM \& Glover JS 1963 The preparation of I-131-labelled human growth hormone of high specific radioactivity. Biochemical Journal 89 114-123.
Groome NP, Illingworth PJ, O'Brien M, Cooke I, Ganesan TS, Baird DT \& McNeilly AS 1994 Detection of dimeric inhibin throughout the human menstrual cycle by two-site enzyme immunoassay. Clinical Endocrinology 40 717-723. (doi:10.1111/j.1365-2265.1994.tb02504.x)

Groome NP, Illingworth PJ, O'Brien M, Pai R, Rodger FE, Mather JP \& McNeilly AS 1996 Measurement of dimeric inhibin B throughout the human menstrual cycle. Journal of Clinical Endocrinology and Metabolism 81 1401-1405. (doi:10.1210/jc.81.4.1401)

Hård K, Mekking A, Damm JB, Kamerling JP, de Boer W, Wijnands RA \& Vliegenthart JF 1990 Isolation and structure determination of the intact sialylated $\mathrm{N}$-linked carbohydrate chains of recombinant human follitropin expressed in Chinese hamster ovary cells. European Journal of Biochemistry 193 263-271. (doi:10.1111/j.1432-1033.1990.tb19332.x)

Horsman G, Talbot JA, McLoughlin JD, Lambert A \& Robertson WR 2000 A biological, immunological and physico-chemical comparison of the current clinical batches of the recombinant FSH preparations Gonal-F and Puregon. Human Reproduction 15 1898-1902. (doi:10.1093/humrep/15.9.1898)

Lanuza GM, Groome NP, Barañao JL \& Campo S 1999 Dimeric inhibin A and $\mathrm{B}$ production are differentially regulated by hormones and local factors in rat granulosa cells. Endocrinology 140 2549-2554. (doi:10.1210/en.140.6.2549)

Loreti N, Ambao V, Juliato CT, Machado C, Bahamondes L \& Campo S 2009 Carbohydrate complexity and proportion of serum FSH isoforms reflect pituitary-ovarian activity in perimenopausal women and depot medroxyprogesterone acetate users. Clinical Endocrinology 71 558-565. (doi:10.1111/j.1365-2265.2009.03559.x)

Loumaye E, Campbell R \& Salat-Baroux J 1995 Human follicle-stimulating hormone produced by recombinant DNA technology: a review for clinicians. Human Reproduction Update 1 188-199. (doi:10.1093/ humupd/1.2.188)

Narasimhan S, Wilson JR, Martin E \& Schachter H 1979 A structure basis for four distinct elution profiles on concanavalin A-sepharose affinity chromatography of glycopeptides. Canadian Journal of Biochemistry and Physiology 57 83-96. (doi:10.1139/o79-011)

Nayudu PL, Vitt UA, Barrios De Tomasi J, Pancharatna K \& Ulloa-Aguirre A 2002 Intact follicle culture: what it can tell us about the roles of FSH glycoforms during follicle development. Reproductive BioMedicine Online 5 240-253. (doi:10.1016/S1472-6483(10)61827-5)

Ogata S, Muramatsu T \& Kobata A 1975 Fractionation of glycopeptides by affinity column chromatography on concanavalin A-sepharose. Journal of Biochemistry 78 687-696.

Padmanabhan V, Lang LL, Sonstein J, Kelch RP \& Beitins IZ 1988 Modulation of serum follicle-stimulating hormone bioactivity and isoform distribution by estrogenic steroids in normal women and in gonadal dysgenesis. Journal of Clinical Endocrinology and Metabolism 67 465-473. (doi:10.1210/jcem-67-3-465)

Sehested A, Juul AA, Andersson AM, Petersen JH, Jensen TK, Müller J \& Skakkebaek NE 2000 Serum inhibin A and inhibin B in healthy prepubertal, pubertal, and adolescent girls and adult women: relation to age, stage of puberty, menstrual cycle, follicle-stimulating hormone, luteinizing hormone, and estradiol levels. Journal of Clinical Endocrinology and Metabolism 85 1634-1640. (doi:10.1210/jc.85.4.1634)

Timossi CM, Barrios-de-Tomasi J, González-Suárez R, Arranz MC, Padmanabhan V, Conn PM \& Ulloa-Aguirre A 2000 Differential effects of the charge variants of human follicle-stimulating hormone. Journal of Endocrinology 165 193-205. (doi:10.1677/joe.0.1650193)

Ulloa-Aguirre A, Espinoza R, Damian-Matsumura P, Larrea F, Flores A, Morales L \& Dominguez R 1988 Studies on the microheterogeneity of anterior pituitary follicle-stimulating hormone in the female rat. Isoelectric focusing pattern throughout the estrous cycle. Biology of Reproduction 38 70-78. (doi:10.1095/biolreprod38.1.70)

Ulloa-Aguirre A, Zambrano E, Timossi C, Olivares A, Quintanar A, Aguinaga M, Díaz-Cueto L \& Méndez JP 1995 On the nature of the follicle-stimulating signal delivered to the ovary during exogenously controlled follicular maturation. A search into the immunological and biological attributes and the molecular composition of two preparations of urofollitropin. Archives of Medical Research 26 S219-S230.

Ulloa-Aguirre A, Timossi C, Damián-Matsumura P \& Dias JA 1999 Role of glycosylation in function of follicle-stimulating hormone. Endocrine 11 205-215. (doi:10.1385/ENDO:11:3:205)

Velasquez EV, Creus S, Trigo RV, Cigorraga SB, Pellizzari EH, Croxatto HB \& Campo S 2006 Pituitary-ovarian axis during lactational amenorrhoea. 
II. Longitudinal assessment of serum FSH polymorphism before and after recovery of menstrual cycles. Human Reproduction 21 916-923. (doi:10.1093/humrep/dei411)

Vitt UA, Kloosterboer HJ, Rose UM, Mulders JW, Kiesel PS, Bete S \& Nayudu PL 1998 Isoforms of human recombinant follicle-stimulating hormone: comparison of effects on murine follicle development in vitro. Biology of Reproduction 59 854-861. (doi:10.1095/biolreprod59.4.854)

Walton WJ, Nguyen VT, Butnev VY, Singh V, Moore WT \& Bousfield GR 2001 Characterization of human FSH isoforms reveals a nonglycosylated $\beta$-subunit in addition to the conventional glycosylated $\beta$-subunit. Journal of Clinical Endocrinology and Metabolism 86 3675-3685. (doi:10.1210/jc.86.8.3675)

Woodruff TK, Besecke LM, Groome N, Draper LB, Schwartz NB \& Weiss J 1996 Inhibin A and inhibin B are inversely correlated to follicle-stimulating hormone, yet are discordant during the follicular phase of the rat estrous cycle, and inhibin A is expressed in a sexually dimorphic manner. Endocrinology 137 5463-5467. (doi:10.1210/en. 137.12.5463)

Xu X, Nagarajan H, Lewis NE, Pan S, Cai Z, Liu X, Chen W, Xie M, Wang W, Hammond S et al. 2011 The genomic sequence of the Chinese hamster ovary (CHO)-K1 cell line. Nature Biotechnology 29 735-741. (doi:10.1038/nbt.1932)
Yding Andersen C, Leonardsen L, Ulloa-Aguirre A, Barrios-De-Tomasi J, Moore L \& Byskov AG 1999 FSH-induced resumption of meiosis in mouse oocytes: effect of different isoforms. Molecular Human Reproduction 5 726-731. (doi:10.1093/molehr/5.8.726)

Zambrano E, Olivares A, Mendez JP, Guerrero L, Díaz-Cueto L, Veldhuis JD \& Ulloa-Aguirre A 1995 Dynamics of basal and gonadotropin-releasing hormone-releasable serum follicle-stimulating hormone charge isoform distribution throughout the human menstrual cycle. Journal of Clinical Endocrinology and Metabolism 80 1647-1656. (doi:10.1210/jc.80. 5.1647)

Zambrano E, Barrios-de-Tomasi J, Cárdenas M \& Ulloa-Aguirre A 1996 Studies on the relative in-vitro biological potency of the naturally-occurring isoforms of intrapituitary follicle stimulating hormone. Molecular Human Reproduction 2 563-571. (doi:10.1093/molehr/2.8.563)

Received 16 June 2012

First decision 6 August 2012

Revised manuscript received 23 October 2012

Accepted 19 November 2012 